Int. J. Adv. Eng. Pure Sci. 2020, I: 57-67

DOI: 10.7240/jeps.605719

RESEARCH ARTICLE / ARAŞTIRMA MAKALESI

\title{
Konut Fiyatını Belirleyen Regresyon Denklemi: Maltepe İlçesi Örneği
}

\author{
Regression Equation Determining House Price: Case Study in Maltepe
}

\author{
Uğur KARTAL ${ }^{1}$ (iD) , Adnan CORUM ${ }^{2}$ \\ ${ }^{1}$ Ümraniye Belediyesi, Yapı Kontrol Müdürlüğ̈̈ \\ ${ }^{2}$ Bahçeşehir Üniversitesi, Endüstri Mühendisliği Bölümü
}

Öz

Gayrimenkul değerlemesi yapılırken, konumsal ve fiziksel birtakım faktörlerin varlığı göz önünde bulundurulmaktadır. Özellikle konut fiyatlarını etkilediği düşünülen etmenlerin birçok çeşitliliğe sahip olması, konutun heterojen özelliğe sahip bir mal olduğunu göstermektedir. Ulaşım altyapı yatırımlarının, gayrimenkul değerine artı bir değer katacağı düşünülür. Buradan hareketle Kadıköy-Pendik metrosunun çoklu doğrusal regresyon analizi ile Maltepe ilçesi konut fiyatlarına olan etkisi incelenmiştir. Çıkan sonuçta ulaşım altyapı yatırımlarının ve buna bağlı olarak ulaşım hizmetine olan uzaklığın, seçilen bölgeler için konut fiyatları üzerinde etkisi olduğu tespit edilmiştir. Bununla birlikte konut fiyatlarına, metro istasyonlarına olan uzaklıklarından daha etkili başka faktörlerin varlığı tespit edilmiştir.

Anahtar kelimeler: Çoklu Regresyon Analizi, Gayrimenkul, Raylı Taşıma Sistemi

\begin{abstract}
While real estate appraisal is performed, the presence of a number of positional and physical factors is taken into consideration. The fact that the factors that affect the housing prices have a wide variety shows that the property is a heterogeneous property. Transportation infrastructure investments are considered to add an added value to the value of real estate. Thus, the effect of Kadıöy-Pendik subway on the house prices of Maltepe district was investigated by multiple linear regression analysis. As a result, it has been determined that transportation infrastructure investments and the distance to transportation services have an impact on housing prices for selected regions. However, other factors have been found to be more effective on housing prices than their distance to metro stations.
\end{abstract}

Keywords: Multi Regression Analysis, Real Estate Property, Rail Transport System

\section{GİRIŞ}

Ulaşım, bir gayrimenkulün kullanım amacını belirlemede önemli bir etmendir ve kendi içinde her ulaşım türü, kentsel mekânı da biçimlendirmede farklı etkiler oluşturur. Ulaşımın gayrimenkuller üzerindeki dinamik değişme potansiyeli etkisi kent bölgesinde hemen kendini gösterir. Bu etki yeni kent merkezlerinin oluşumuna ya da kent merkezlerinin kaymasına neden olabilir.

Kentsel gelişmeler ve değişimler ulaşım sistemlerini şekillendirmektedir. Ulaşım sistemlerinin özellikleri de kentsel gelişmeleri ve değişimleri şekillendirmektedir. Bu durumda kent ve ulaşım sistemleri arasında karşıllıklı bir etkileşim bulunmaktadır. Gelişim düzeyi ve yaşam standartları yüksek olan dünya kentleri incelendiğinde, kent içi ulaşım sistemi ile kent planlanmasının bir bütün olarak ele alınması gerekliliğine 1950’li yıllarda farkına varılmış, toplu taşıma sistemleri bu planlama doğrultusunda değerlendirilmiştir. Sanayinin özellikle büyükşehirlerde gelişmesi, 1960’lı yıllarda kırsaldan şehirlere büyük göç dalgaları meydana getirmiştir. Hem yeni yerleşim alanlarının doğması hem de artan nüfus, düşük kapasiteli ve sınırlı toplu taşımacılığın yerine, yeni ulaşım altyapı sistemlerinin kurulup, geliştirilmesini gerekli kılmıştır. 
Kentin gelecekteki ulaşım sisteminin insanların ekonomik, hızlı, konforlu ve güvenli bir şekilde ulaşımına öncelik verilerek planlanması gerekmektedir. Bu amaçla kent içi ulaşımın temel öğesi olan toplu taşımanın hız, yolculuk süresi, konfor, güvenirlilik, güven ve maliyet unsurlarından oluşan hizmet düzeyini yükseltmek ve bulunabilirliğini artırmak raylı sistem yatırımları ile mümkündür. Kalıcı altyapıya sahip bu yüksek kapasiteli toplu taşıma sistemleri İstanbul gibi metropollerde güncel problem olan trafik sorununa iyi bir çözümdür. Raylı sistemlerin tercih edilme nedenleri arasında beklentileri karşılayabilmesi, çevreye duyarlı olması, ekonomik olması, yolculuk sürelerini azaltması, trafik sıkışıklığını ortadan kaldırması ve diğer ulaşım türlerine göre daha konforlu olması sayılabilir.

Şehir içi taşımada kullanılan araçların yolcu taşıma kapasiteleri incelendiğinde en büyük paya sahip hatların, raylı sistemlere entegre bir şekilde çalışan araçlar olduğu görülmektedir. Bir gayrimenkulün değerini etkiyen konumsal faktörlerden ulaşım en çok metro, tramvay gibi raylı sistemlerden etkilenmektedir.

Ülkemizde, büyük şehirlerde oluşan yoğunluk ve nüfus artışı, trafik sorununu getirmektedir ve bunun sonucu olarak kent içi raylı sistem yatırımları hızla artmaktadır. Başta İstanbul olmak üzere birçok şehirde raylı sistem projeleri hayata geçirilmiş veya devam etmektedir. Ülkemizde raylı sistem yatırımlarının, gelişmiş ülkelere nazaran yeni yatırımlar olması nedeniyle, arazinin kullanım amacı, bölgesel yoğunluk ve değerlenme, nüfus gibi uzun döneme yayılacak değişimlerin ölçülmesi, gelecekte yapılacak çalışmalar açısından önemli bir referans olacaktır.

Konut fiyatını etkileyen en önemli etken kent merkezine olan mesafe ve ulaşım seçenekleridir. Transit istasyona yakın konumlanmış gayrimenkul birim değerinin, artan erişebilirlik düzeyinden dolayı yüksek olması beklenmektedir. $\mathrm{Bu}$ sebeple ulaşım alt yapısındaki yatırımlar ile gayrimenkul değeri arasında güçlü bir ilişki vardır. Ulaşım yatırımlarının en önemli amacı kentteki hareket ve erişebilirlik düzeyini artırmaktır. Böylece seyahat süresinde kazanılan zaman ve artan erişebilirlik, kentsel gelişimin ulaşım hatları ile paralellik göstermesini sağlar.

Ulaşım imkanlarına yakınlık, yapılan birçok araştırmada gayrimenkul ediniminde, ilk tercih olmuştur. GYODER' in 2013 yılında yapmış olduğu ankete göre özellikle İstanbul'un geçmişten bu yana süregelen trafik sorunundan dolayı, konut satın alırken alıcıların göz önünde bulundurdukları ilk kriter ulaşım kolaylığıdır. Yapılan ankete İstanbul'un farklı semtlerinde oturan 5000 kişi katılmış olup, katılımcılara konut alma aşamasında hangi kriterleri göz önünde bulundurdukları sorulmuştur. Çıkan anket sonucuna göre ulaşım kolaylığı yaklaşık \%38,7 oran ile ilk sırada yerini almıştır. Anket sonucu Tablo 1'de gösterilmiştir.

Tablo 1. Konut alırken dikkat edilen hususlar (GYODER, 2013)

\begin{tabular}{|c|c|c|c|}
\hline Sıra & $\begin{array}{c}\text { Konut alırken dikkat edilen } \\
\text { hususlar }\end{array}$ & $\begin{array}{c}\text { İlk sırada } \\
\text { verilen } \\
\text { cevaplar }\end{array}$ & $\begin{array}{c}\text { İlk sıra } \\
\text { oranı } \\
\mathbf{( \% )}\end{array}$ \\
\hline 1 & Ulaşım kolaylı̆̆ & 1943 & 38,7 \\
\hline 2 & Sosyal çevre & 1141 & 22,8 \\
\hline 3 & Depreme dayanıklılık-sağlamlık & 406 & 8,1 \\
\hline 4 & Bulunduğu yer-semt & 330 & 6,6 \\
\hline 5 & Otopark & 320 & 6,4 \\
\hline 6 & Fiyat & 236 & 4,7 \\
\hline 7 & Yeşil alan & 178 & 3,5 \\
\hline 8 & Sosyal imkanlar & 150 & 3 \\
\hline 9 & Güvenlik & 78 & 1,6 \\
\hline 10 & Yeni bina olmas1 & 52 & 1 \\
\hline 11 & Aidat & 37 & 0,7 \\
\hline 12 & Diğer & 144 & 2,9 \\
\hline Toplam & & $\mathbf{5 0 1 5}$ & $\mathbf{1 0 0}$ \\
\hline
\end{tabular}

En genel tanıma göre taşınmaz değerlemesi, taşınmaz malın belli bir tarihteki imar durumu, konumu, zemin ve inşaat yapısı, elde edilen gelir, ulaşım imkânı, alt yapı durumu, parselin şekli, boyutu, genişliği gibi değeri etkileyen bütün unsurların dikkate alınarak değerinin para cinsinden ifade edilmesidir.

Taşınmaz değerleme sürecinin sonunda ulaşılmaya çalışılan, değerlendirilen taşınmazın piyasa değerini etkileyen faktörlerin tümünü göz önüne alan ve her yönüyle desteklenen bir değere ulaşmaktır. Değerleme yöntemleri olarak tanımlanan bu yaklaşımlar Şekil 1'de gösterilmiştir. Taşınmaz değerlemesinde en çok kullanılan yöntemlerden birisi istatiksel değerleme yöntemidir. Bu yöntemin esası, taşınmaz değeri ve taşınmaz kriterleri arasındaki sayısal ya da oransal bağıntılar ile matematiksel model oluşturmaktır. Bu yöntemde kullanılan analizler regresyon analizi, hedonik yaklaşım ve nominal yöntem olarak sıralanabilir (Yalpır, 2007).

Dünyada ve ülkemizde metroya olan uzaklığın konutların fiyatlarına etkisi ile ilgili yapılan çalışmaların birçoğu incelenerek, konutun fiziksel özelliklerinin yanında konumsal özelliklerinin de konut fiyatları üzerinde etkili olduğu görülmüştür. $\mathrm{Bu}$ çalışmada veri setlerinden faydalanıldığı ve istatistiksel oranlar açıklanmak istendiği için çalışma yöntemi olarak istatistiksel yöntemlerden birisi olan regresyon analizi kullanılmıştır. Çalışmanın amacı Maltepe ilçesinde bulunan konutların fiziksel özelliklerinin yanı sıra Kadıköy-Pendik metrosuna olan uzaklıklarının, konut fiyatlarını 
ne şekilde etkilediğini çoklu doğrusal regresyon analizi ile belirlemektir.

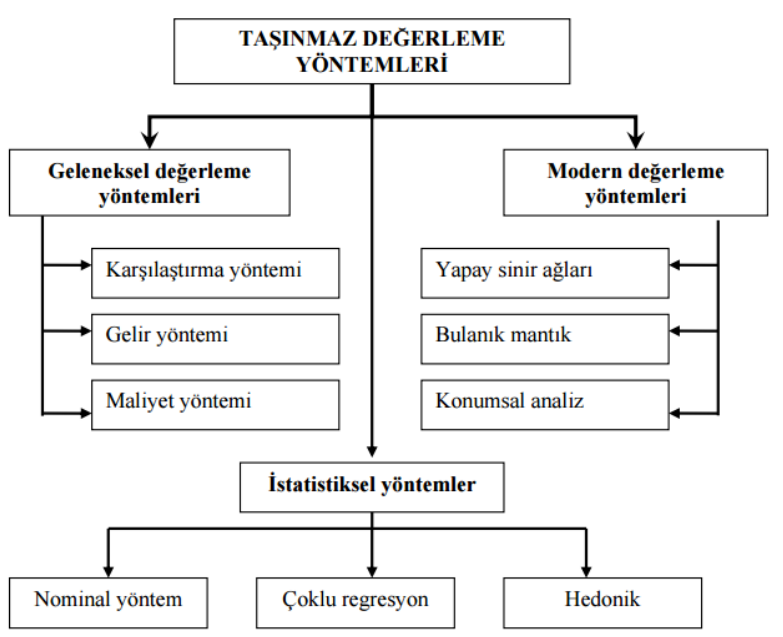

Şekil 1. Taşınmaz değerleme yöntemleri (Yalpır, 2007)

Regresyon analizi sonucunda Maltepe ilçesi iki bölgeye ayrılarak her iki bölge için ayrı ayrı genel bir denklem bulunarak Kadıköy-Pendik metrosunun konut fiyatları üzerindeki etkisi istatistiksel olarak belirlenmiştir. Bu denklem yardımıyla konutlar için yaklaşık bir fiyat belirlenebilecektir. Yapılan analizde kullanılan konut fiyatları, 2016 y1lı verileri kullanılarak üretilmiştir. Konut fiyatlarını etkileyen faktörler konutun oda sayısı, büyüklüğü, bulunduğu kat gibi fiziksel özelliklerinin yanı sıra metroya olan uzaklığı ile birlikte incelenmiştir.

Çalışma bölgesinde örneklem olarak seçilmiş satışta olan 415 apartman dairesinin fiyatlarını etkileyen faktörler regresyon analizi ile araştırılmıştır. İki bölgeye ayrılmış Maltepe ilçesi için yapılan regresyon analizinden sonra, birinci bölge Fındıklı, Aydınevler, Zümrütevler, Gülsuyu, Gülensu, Esenkent ve Girne mahallelerini kapsamaktadır. İkinci bölge ise Altıntepe, Küçükyalı, Çınar, İdealtepe, Altayçeşme, Cevizli, Feyzullah, Yalı ve Bağlarbaşı mahallelerini kapsamaktadır. Birinci bölgede toplam 118 konut, ikinci bölgede toplam 297 konut için regresyon analizi yapılarak sonuçlar irdelenmiştir.

Çalışmanın bundan sonraki bölümleri şu şekilde organize edilmiştir: Bölüm 2'de literatür taraması sunulmuştur. Bölüm 3'te konut fiyatlarını etkileyen fiziksel özelliklerin yanında konutların metroya olan uzaklıklarının fiyatları üzerindeki etkisi araştırılarak Maltepe ilçesi için bir regresyon denklemi bulunmuştur. Bölüm 4'te analiz edilen konutların özellikleri sunulmuştur. Bölüm 5'te yapılan çalışmanın sonuçları ile birlikte öneriler sunulmuştur.

\section{LITERATÜR TARAMASI}

Ulaşım alt yapı yatırımları ile ilgili projeler oluşturulurken göz önünde bulundurulması gereken hususlar ve hususların gayrimenkul piyasası üzerinde meydana getirdiği etki ile alakalı Türkiye'de yapılan çalışmaların sayısı azdır. Literatürde bazı yabanc1 uygulamalar da mevcuttur.

Damm ve diğ. (1980) Washington metrosunun kentsel gayrimenkul değerlerine etkisi olup olmayacağını araştırmışlardır. Veriler, sahibi tarafından oturulan tek kişilik müstakil evler, apartmanlar ve alışveriş kuruluşları olmak üzere 3 gruba ayrılmış ve 1969-1976 yılları arasından toplanmıştır. Analiz sonucunda her üç grup içinde metroya olan yakınlık arttıkça gayrimenkulün fiyatının azaldığını tespit etmişlerdir. Forrest ve diğ. (1996) çalışma bölgesi olarak İngiltere'nin kuzeyindeki Manchester şehrini seçmişlerdir. Çalışma, metronun açılmasından dört yıl sonra 1996 yılında yapılmıştır. Verileri, ülke çapında yapı kooperatifinden alarak 1990 yılında satılmış olan 795 tane mortgage verisi için analiz yapmışlardır. Verileri yapı özellikleri, komşuluk özellikleri ve yapının konumu olarak 3 bölüme ayırmışlardır. Yapı özellikleri olarak; kullanım süresi, yaşı, yatak odası sayıs1, garajı olup olmadığı, konut tipi (teraslı, müstakil, apartman dairesi, bungalov) ve isınma gibi karakteristikleri belirlemişlerdir. Komşuluk özelliklerini, nüfus ve alışveriş merkezi, okul gibi yapılara olan uzaklık olarak ikiye ayırmışlardır. Yapının konumunda ise, konutun istasyona olan uzaklığını Pisagor teoremiyle hesaplamışlardır. Elde ettikleri sonuçlara göre, istasyona yakın konutların fiyatlarının daha düşük olduğunu gözlemlemişlerdir. Cervero (2003) hafif raylı toplu taşıma ve banliyö demir yolu taşımasının arazi fiyatları üzerindeki etkisini araştırmıştır. Çalışma bölgesi olarak ABD'nin 9. büyük şehri olan San Diego'yu seçmiştir. Hafif raylı toplu taşıma istasyonlarına olan yakınlığın oturmaya elverişli arazilerin değerini doğrudan arttırdığı ve banliyö demir yolu istasyonlarına olan uzaklığın ise arazinin fiyatını olumsuz yönde etkilediği tespit edilmiştir. Debrezion ve diğ. (2004) demiryolu istasyonlarının ticari ve konutsal gayrimenkul değerleri üzerindeki etkisini araştırmışlardır. Çalışma bölgesi olarak Batı ABD, Orta Amerika, Avrupa ve Doğu ABD'yi seçmişlerdir. İstasyonları, hizmet sıklığı, toplanma alanları, teknolojik üstünlük ve yolcu kapasiteleri gibi özelliklerinin aynı olmayacağı ve bunun da emlak değerini etkileyeceğini düşünerek dekovil hattı (hafif demiryolu), metro (ağır demiryolu), banliyö tren ve metrobüs olarak dört bölüme ayırmışlardır. Elde ettikleri bulgularda, demiryolu istasyonlarına olan yakınlığın ticari gayrimenkul değerlerini konutsal gayrimenkul değerlerine göre daha çok arttırdığını ve banliyö trenlerin diğer istasyonlara göre daha yüksek bir etkiye sahip olduğunu tespit etmişlerdir. Yankaya ve Çelik (2005) İzmir metrosu örneğini incelemişlerdir. Konutun 
farklı özelliklere sahip heterojen bir mal olduğunu ve bu heterojen malı oluşturan her bir karakteristiğin fiyatın belirlenmesinde etkili olacağını düşünerek bir fiyat modeli uygulamışlardır. Modellemenin neticesinde metroya yakın olan konut satış fiyatlarının artış eğiliminde olduğu gözlenmiştir. Debrezion ve diğ. (2006) Hollanda'da demiryolu ulaşımının gayrimenkul değerleri üzerindeki etkisini araştırmışlardır. Verileri 1985-2001 yılları arasındaki konut fiyatlarından almışlardır. Yaptıkları analizde, bağımlı değişkeni fiyat almış, bağımsız değişkenleri ise konutun fiziksel özellikleri (yaş, metrekare vb.), ulaşılabilirlik özellikleri (demiryolu istasyonuna olan uzaklığı, otoban giriş - çıkışına olan uzaklığı, en sık kullanılan demiryolu istasyona olan uzaklık vb.), çevresel özellikleri (nüfus vb.) olarak üç kısma ayırmışlardır. Elde ettikleri analiz sonuçlarına göre, istasyona yakın olan konutun uzak olana göre fiyatı ortalama $\% 25$ daha pahalıdır. İstasyona $1,5 \mathrm{~km}$ veya daha uzak mesafedeki konutların fiyatı, istasyon frekans sayısına göre $\% 19$ ve $\% 33$ arasında değişmektedir. Demiryolu istasyonlarına $250 \mathrm{~m}$ kadar yakınlıkta olan istasyonların fiyatı ise $500 \mathrm{~m}$ 'den fazla uzaklıkta olan konutlara göre $\% 5$ daha düşüktür. Bunun nedeninin gürültü olabileceği belirtilmiştir.

Troncoso ve diğ. (2010), Barcelona'daki kentsel ve ulaŞım projelerinin gayrimenkul değerleri üzerindeki etkisini araştırmışlardır. Çalışma bölgesindeki 1262 konuttan 169'u seçilerek analiz yapılmıştır. Ulaştırma projelerinin seçimi için 2001-2010 yılları arasındaki ulaştırma altyapı mastır planı tarafından türetilen bilgileri kullanmışlardır. Elde ettikleri analiz sonuçlarına göre, ulaştırma projelerinin gayrimenkul değerleri üzerinde negatif etkisi olduğunu buna karşılık kentsel projelerin ise pozitif etkisi olduğunu tespit etmişlerdir. Boucq (2011) hafif demir yolu altyapısının konut fiyatları üzerindeki etkisini araştırmıştır. Çalışma bölgesi olarak Paris'in batısındaki Hauts-de-Seine bölgesini seçmiştir. Yılları 1993-1995, 1996-2000 ve 2001-2004 olmak üzere üç gruba ayırmıştır. Hafif demir yolunun konut fiyatları üzerinde sabit bir etkisi olduğu ve konut fiyatlarını yaklaşık \%9 oranında artırdığı gözlemlenmiştir.

Christopher ve diğ. (2012) çalışma bölgesi olarak Kanada'nın başkenti ve dördüncü büyük kenti olan Ottawa'yı seçmişlerdir. Yaklaşık 80.000 satılık konut bilgileri üzerinden 3735 tanesi analize sokulmuştur. Analizde bağımlı değişken olarak konutun fiyatı, bağımsız değişkenler olarak konutun oda sayıs1, yatak odası sayıs1, konutun metre karesi, konut tipi, bodrum kat sayısı, garaj sayısı, konutun yaşı, park yeri, konutun vergisi, en yakın su kaynağına olan uzaklığı, en yakın parka olan uzaklığı, nüfus sayısı, toplam kaç kişinin raylı sistemi kullandığı ve raylı sisteme olan yürüme mesafesi olarak belirlenmiştir. Elde ettikleri sonuçlara göre, komşuluk, konum ve raylı sistemlere olan uzaklıklarına göre konut fiyatının olumlu yönde etkilenmediğini belirtmişlerdir. Bin (2012) metro istasyonlarının arazi fiyatları üzerindeki etkisini araştırmıştır. Çalışma bölgesi olarak Çin' in Pekin şehrini seçmiştir. Verileri 2004 ve 2011 yılları arasından toplamıştır. Arazi kullanımını, konutsal özellikte olanlar, ticari özellikte olanlar ve diğerleri olmak üzere üç kısma ayırmıştır. Uzaklıkları ise alt merkeze ve istasyona olan uzaklık olarak iki kısma ayırmıştır. Elde ettiği sonuçlara göre, endüstriyel araziler hariç tüm arazi kullanım türleri için en yakın metro istasyonuna olan uzaklığın fiyatları arttırdığını bulmuştur.

National Association of Realtors 2013 yılında açıkladığı raporda, toplu taşıma araçlarına olan uzaklığın konut fiyatları üzerindeki etkisini araştırmıştır. Çalışma bölgesi olarak ABD’nin Boston, Chicago, Minneapolis - St. Paul, Phoneix ve San Francisco kentleri seçilmiştir. Tüm bölgeler için 2006-2011 yılları arasındaki veriler kullanılmıştır. Toplu taşıma araçları, ağır demiryolu (metro), hafif demiryolu (dekovil hattı) ve metrobüs olmak üzere üç kısma ayırılmışlardır. Elde ettikleri sonuçlara göre, ulaşımın kolay sağlandığı bölgelerde, sağlanmayanlara göre konut fiyatlarının daha fazla olduğu gözlemlenmiştir. İnanoğlu (2014) raylı taşıma sisteminin konut fiyatları üzerindeki değişimini incelemiş, raylı sistem hattının geçtiği güzergâh üzerinde bulunan altı mahalle belirlenerek, bu mahallelerin belirli bir dönem aralığı için konut endeks değerleri analiz edilmiştir. Çalışmanın sonucunda, bazı dönemlerde, konut fiyatlarını ulaşımdan daha çok etkileyen diğer faktörlerin varlığı tespit edilmiştir.

Türkiye'de ve diğer ülkelerde yapılan araştırmalarda, raylı sistem alt yap1 yatırımlarının, gayrimenkuller üzerinde olumlu etkilerinin olabileceği gözlemlendiği gibi negatif etkilerinin de olabileceği ortaya konmuştur. Bununla birlikte, kullanım amacına göre ofis, konut, ticari nitelikli yapılar gibi gayrimenkullerin, kendi alt kategorileri içerisinde zaman ve mekân şartları açısından farklı etkileşim gösterdikleri ve konumsal etkiden ziyade gürültü, daire büyüklüğü, yapı sınıfı gibi daha güçlü parametrelerin varlığı tespit edilmiştir.

\section{REGRESYON MODELI}

1987'de Kartal ilçesinden ayrılıp müstakil ilçe olan Maltepe, İstanbul iline bağlı Marmara Denizi’ne kıyısı olan, Anadolu yakasında bir ilçedir. İstanbul ili sınırları dahilinde 5747 Sayılı Kanun kapsamında oluşturulan 39 ilçeye ait alan ve nüfus bilgilerine göre Maltepe'nin kara alanı $52,97 \mathrm{~km}^{2}$ olup 18 mahalleden oluşmaktadır. İlçe nüfusu ise 471.059'dur (IBBB, 2016). Şekil 2'de gösterildiği üzere Kadıköy, Kartal, Sancaktepe ve Ataşehir ilçeleriyle komşudur. 


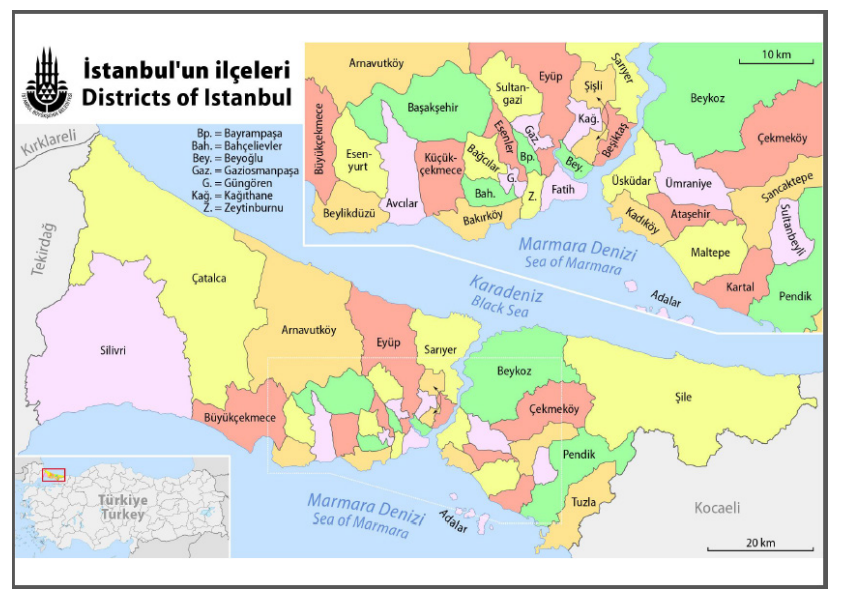

Şekil 2. Maltepe ilçe sınırları (İBB)

Kadıköy-Pendik Metrosu (M4) İstanbul'da Anadolu Yakası'nın ilk metro hatıdır. Metronun açılmasıyla beraber birçok semtte gayrimenkul fiyatlarında artış kaydedilmiştir.
Şekil 3'de Maltepe ilçesinin 2015 ve 2016 yılları arasında satılık konut ortalama $\mathrm{m}^{2}$ birim fiyatı görülmektedir. Konutların fiyatlarına etki ettiği düşünülen parametreler aşağıdaki gibi belirlenmişsir.
a. Konutun yaşı
b. Konutun oda sayis1
c. Konutun metrekaresi
d. Binanın kat sayısı
e. Binanın kaçıncı katında olduğu
f. En yakın metro istasyonuna olan uzaklığ

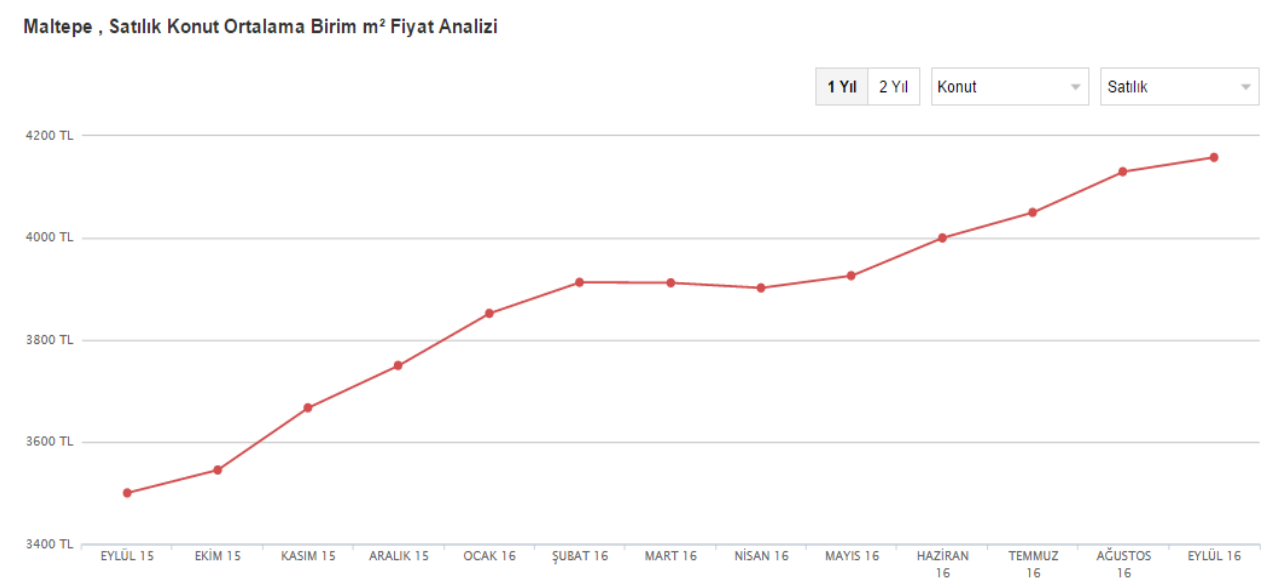

Şekil 3: Maltepe ilçesi satılık konut ortalama birim $\mathrm{m}^{2}$ fiyat analizi (hurriyetemlak.com, 2016)

Çalışma bölgesi incelendiğinde, E5 aksının üst kısmında kalan mahallelerdeki konutlar ile E5 aksının alt kısmında (sahil bölgesi) kalan konut fiyatları arasında belirgin farkl1lıklar olduğu tespit edilmiştir. Bu sebepten Maltepe ilçesini bir bütün olarak incelemek yerine ikiye ayırmak daha uygundur. E5 aksının üst kısmındaki bölge birinci bölge olarak, E5 aksının alt kısmındaki bölge ise ikinci bölge olarak isimlendirilmiştir. Birinci bölgede 118 konut ve ikinci bölgede 297 konut olmak üzere toplamda 415 tane satılık konut için konumsal ve fiziksel altı adet parametre ile regresyon analizi yapılmıştır. Konutun yaşı, metrekaresi gibi fiziksel özellikleri, Hürriyet Emlak sitesinde verilen satıllk ilanlarından temin edilmiştir. Konutun metroya olan uzaklığı ise kendisine en yakın metro istasyonuna olan kuşbakışı uzaklığıdır.

Kenan Evren Kışlası'nın Başıüyü̈k Mahallesi sınırları içerisinde, Nurettin Baransel Kışlası'nın ise Büyükbakkalköy Mahalle sınırları içerisinde kalmasından dolayı bu mahallelerde konut satış ilanına rastlanmamıştır. Bu nedenle Başıbüyük ve Büyükbakkalköy Mahalleleri uygulamaya dahil edilmemiştir. Uygulama alanı Şekil 4'de gösterilmiştir. 


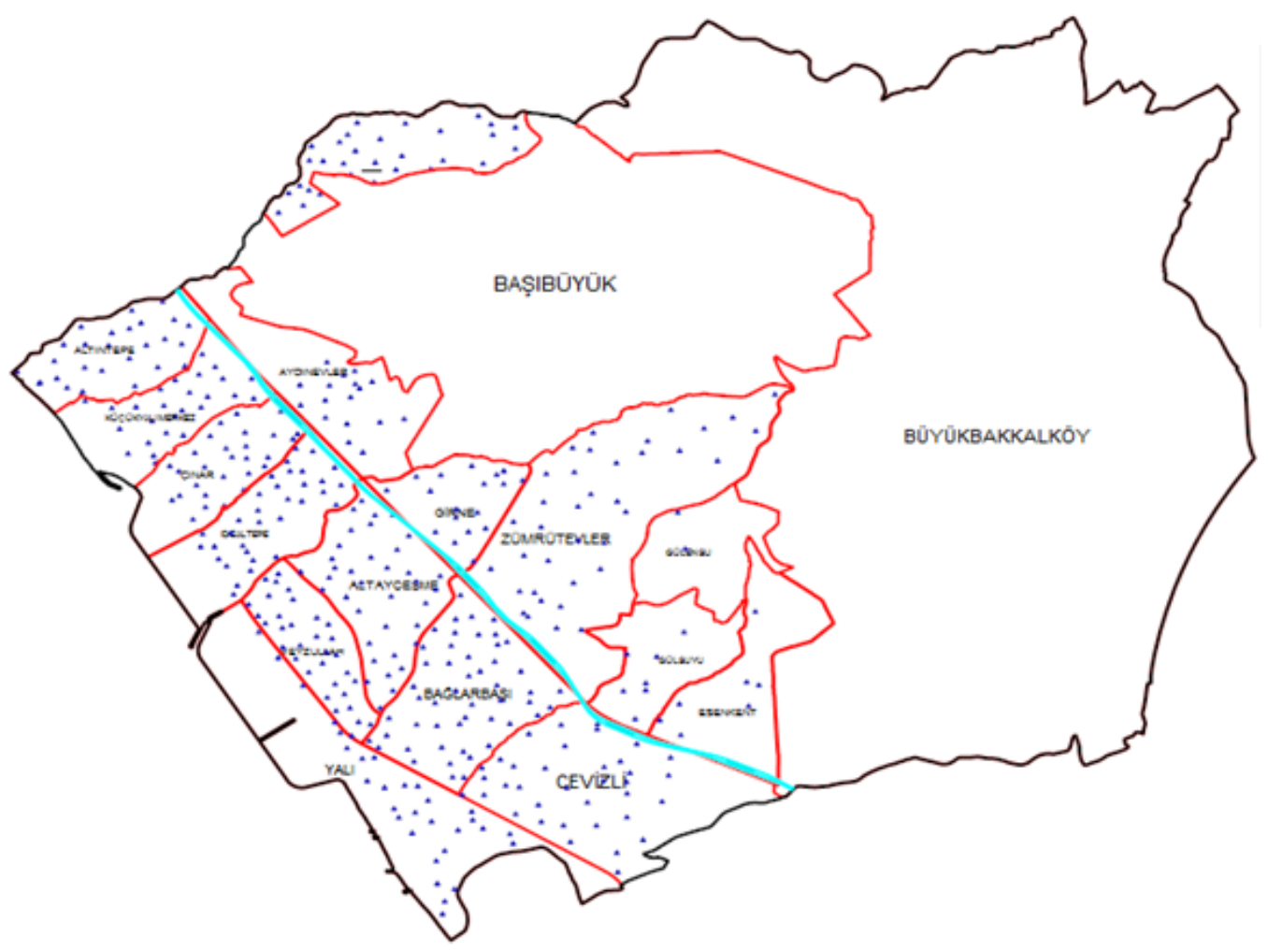

Şekil 4. Uygulama alanı

Konut fiyatları arasında belirgin farklılıkların olduğu birinci ve ikinci bölgeler için Model 1 ve Model 2 olmak üzere iki farklı regresyon modeli oluşturulmuştur. Bunun nedeni, birbirinden net bir şekilde farklı olan iki bölge için oluşturulacak modelde bağımsız değişkenlerin bağımlı değişkeni farklı katsayılarla etkileyeceğidir. İki model için de istatistiksel olarak anlamlı çıktığı sürece aynı bağımlı değişken ve bağımsız değişkenler kullanılmıştır. Regresyon modeli için kullanılan değişkenler Tablo 2' de verilmiştir.

Tablo 2. Değişkenler

\begin{tabular}{|l|l|}
\hline Bağımlı Değişken & Bağımsız Değişken \\
\hline Konutun fiyatı (F) & $\begin{array}{l}\text { Konutun yaşı (Y) } \\
\text { Konutun metrekaresi (M) } \\
\text { Konutun oda sayısı (O) } \\
\text { Konutun kaçıncı katta olduğu (K) } \\
\text { Binanın kat sayısı (B) } \\
\text { Konutun en yakın metro istasyonuna olan uzak- } \\
\text { lı̆ğ (U) }\end{array}$ \\
\hline
\end{tabular}

Model 1'de konut fiyatını etkileyen parametrelerin (Y, M, O, $\mathrm{K}, \mathrm{B}$ ve U) konut fiyatıyla (F) olan ilişkisi incelenmiştir. Elde edilen sonuçlar Tablo 3, Tablo 4 ve Tablo 5'de gösterilmiştir.

Tablo 3. Model 1 katsayılar tablosu

\begin{tabular}{|c|c|c|c|c|}
\hline & Katsayılar & Standart Hata & t Stat & P-değeri \\
\hline Kesişim & 11,15 & 2,49 & 4,48 & ${ }_{0}$ \\
\hline $\mathbf{O}$ & 0,01 & 0,08 & 0,09 & 0,93 \\
\hline $\mathbf{M}$ & 0,47 & 0,10 & 4,81 & ${ }_{0} 0$ \\
\hline $\mathbf{Y}$ & $-0,06$ & 0,04 & $-1,73$ & 0,09 \\
\hline $\mathbf{B}$ & 0,28 & 0,06 & 5,08 & ${ }_{0} 0$ \\
\hline $\mathbf{K}$ & 0,03 & 0,07 & 0,50 & 0,62 \\
\hline $\mathbf{U}$ & $-0,12$ & 0,02 & $-5,50$ & ${ }_{0}$ \\
\hline
\end{tabular}

Tablo 4. Model 1 regresyon istatistikleri

\begin{tabular}{|c|c|}
\hline Çoklu R & 0,79 \\
\hline $\mathbf{R}^{\mathbf{2}}$ & 0,63 \\
\hline Ayarlı R $^{\mathbf{2}}$ & 0,61 \\
\hline Standart Hata & 6,07 \\
\hline Gözlem & 118 \\
\hline
\end{tabular}


Tablo 5. Model 1 ANOVA tablosu

\begin{tabular}{|c|c|c|c|c|c|}
\hline & df & SS & MS & F & Anlamlılık F \\
\hline Regresyon & 6 & 6893,86 & 1148,98 & 31,20 & $z_{0}$ \\
\hline Fark & 111 & 4087,75 & 36,83 & & \\
\hline Toplam & 117 & 10981,60 & & & \\
\hline
\end{tabular}

Tablo 3' de verilen P değerlerinden M, Y, B ve U \%90 güvenirlik düzeyinde istatistiksel olarak anlamlıdır. $\mathrm{O}$ ve $\mathrm{K}$ \%90 güvenirlik düzeyinde istatistiksel olarak anlamlı çıkmadığından modelden çıkarılmış ve Model 1 revize edilerek Tablo 6, Tablo 7 ve Tablo 8'de gösterilmiştir.

Tablo 6. Model $1_{\text {revize }}$ katsay1lar tablosu

\begin{tabular}{|c|c|c|c|c|}
\hline & Katsayılar & Standart Hata & $\mathbf{t}$ Stat & P-değeri \\
\hline Kesişim & 11,17 & 2,20 & 5,07 & $z_{0}$ \\
\hline $\mathbf{M}$ & 0,49 & 0,04 & 11,09 & $\tilde{}_{0}$ \\
\hline $\mathbf{Y}$ & $-0,06$ & 0,03 & $-1,75$ & 0,08 \\
\hline $\mathbf{B}$ & 0,30 & 0,04 & 6,86 & ${ }_{0} 0$ \\
\hline $\mathbf{U}$ & $-0,12$ & 0,02 & $-5,55$ & ${ }_{0}$ \\
\hline
\end{tabular}

Tablo 7. Model $1_{\text {revize }}$ regresyon istatistikleri

\begin{tabular}{|c|c|}
\hline Çoklu R & 0,79 \\
\hline $\mathbf{R}^{\mathbf{2}}$ & 0,63 \\
\hline Ayarlı $\mathbf{R}^{\mathbf{2}}$ & 0,61 \\
\hline Standart Hata & 6,02 \\
\hline Gözlem & 118 \\
\hline
\end{tabular}

Tablo 8. Model $1_{\text {revize }}$ ANOVA tablosu

\begin{tabular}{|c|c|c|c|c|c|}
\hline & df & SS & MS & F & Anlamlılık F \\
\hline Regresyon & 4 & 6884,01 & 1721 & 47,46 & $z_{0}$ \\
\hline Fark & 113 & 4097,60 & 36,26 & & \\
\hline Toplam & 117 & 10981,61 & & & \\
\hline
\end{tabular}

Model $1_{\text {revize }}$ için elde edilen konut fiyatı denklemi aşağıda gösterilmiştir:

Konut fiyatı $(\mathrm{F})=11,17+0,49 * \mathrm{M}-0,06 * \mathrm{Y}+0,30 * \mathrm{~B}-0,12 * \mathrm{U}$

Model $1_{\text {revize }}$ 'ye ilişkin elde edilen bulgular aşağıdaki gibidir: a. İncelenen örneğe ait $\mathrm{R}^{2}=0,63$ çıkmıştır. Kullanılan bağımsız değişkenlerin (M, Y, B ve U) konut fiyatındaki (F) toplam varyasyonu açıklayabilme oranı \%63'dür. Kalan \%37'lik kısım bilinmeyen faktörler nedeniyle oluşmuştur.

b. $\mathrm{R}^{2}$ değeri 0,5-0,7 aralığında çıktığı için F ile M, Y, B ve $U$ arasında orta dereceli ilişki vardır.

c. Ayarlı $\mathrm{R}^{2}=0,61$ çıkmıştır ve $\mathrm{R}^{2}$ ile neredeyse aynıdır. Bu durumda modeli oluşturmak için gözlem sayısının yeterli olduğu söylenebilir.

d. $F=47,46$ için P değeri 0,1 'den çok küçük olduğu için model genel olarak yüksek derecede anlamlı çıkmıştır.

e. F ile $\mathrm{M}$ ve $\mathrm{B}$ arasında pozitif korelasyon vardır. Yani konut büyüdükçe ve bulunduğu apartman yükseldikçe konutun fiyatı artmaktadir.

f. F ile $\mathrm{Y}$ ve $\mathrm{U}$ arasında negatif korelasyon vardır. Yani konutun yaşı arttıkça ve metrodan uzaklaştıkça fiyatı azalmaktadir.

Model 2'de konut fiyatını etkileyen parametrelerin (Y, $\mathrm{M}, \mathrm{O}, \mathrm{K}, \mathrm{B}$ ve U) konut fiyatıyla (F) olan ilişkisi incelenmiştir. Elde edilen sonuçlar Tablo 9, Tablo 10 ve Tablo 11'de gösterilmiştir.

Tablo 9. Model 2 katsayılar tablosu

\begin{tabular}{|c|c|c|c|c|}
\hline & Katsayılar & Standart Hata & t Stat & P-değeri \\
\hline Kesişim & 1,80 & 2,46 & 0,73 & 0,46 \\
\hline $\mathbf{O}$ & 0,15 & 0,08 & 1,84 & 0,07 \\
\hline $\mathbf{M}$ & 0,60 & 0,09 & 7,05 & $\approx_{0}$ \\
\hline $\mathbf{Y}$ & $-0,15$ & 0,02 & $-7,77$ & $\mathbf{z}_{0}$ \\
\hline $\mathbf{B}$ & 0,17 & 0,04 & 3,92 & $\approx_{0}$ \\
\hline $\mathbf{K}$ & 0,13 & 0,06 & 2,35 & 0,02 \\
\hline $\mathbf{U}$ & 0,19 & 0,03 & 5,57 & $\mathbf{z}_{0}$ \\
\hline
\end{tabular}

Tablo 10. Model 2 regresyon istatistikleri

\begin{tabular}{|c|c|}
\hline Çoklu R & 0,80 \\
\hline $\mathbf{R}^{\mathbf{2}}$ & 0,65 \\
\hline Ayarlı $\mathbf{R}^{\mathbf{2}}$ & 0,64 \\
\hline Standart Hata & 8,22 \\
\hline Gözlem & 297 \\
\hline
\end{tabular}


Tablo 11. Model 2 ANOVA tablosu

\begin{tabular}{|c|c|c|c|c|c|}
\hline & Df & SS & MS & F & Anlamlılı F \\
\hline Regresyon & 6 & 35640,09 & 5940,01 & 87,81 & ${ }_{0}$ \\
\hline Fark & 290 & 19617,13 & 67,65 & & \\
\hline Toplam & 296 & 55257,21 & & & \\
\hline
\end{tabular}

Tablo 9'da verilen P değerlerinden O, M, Y, B, K ve U $\% 90$ güvenirlik düzeyinde istatistiksel olarak anlamlıdır. Model 2 için elde edilen konut fiyatı denklemi ve elde edilen bulgular aşağıdaki gibidir.

Konut fiyat $(\mathrm{F})=1,80+0,15 * \mathrm{O}+0,60 * \mathrm{M}-0,15 * \mathrm{Y}+$ $0,17 * \mathrm{~B}+0,13 * \mathrm{~K}+0,19 * \mathrm{U}$

a. İncelenen örneğe ait $\mathrm{R}^{2}=0,65$ çıkmıştır. Kullanılan bağımsız değişkenlerin ( $\mathrm{O}, \mathrm{M}, \mathrm{Y}, \mathrm{B}, \mathrm{K}$ ve $\mathrm{U})$ konut fiyatındaki (F) toplam varyasyonu açıklayabilme oranı oransal olarak \%65'dir. Kalan \%35'lik kısım bilinmeyen faktörler nedeniyle oluşmuştur.

b. $\mathrm{R}^{2}$ değeri $0,5-0,7$ aralığında çıtı $\mathrm{B}, \mathrm{K}$ ve $\mathrm{U}$ arasında orta dereceli ilişki vardır.

c. Ayarlı $\mathrm{R}^{2}=0,64$ çıkmıştır ve $\mathrm{R}^{2}$ ile çok yakındır. $\mathrm{Bu}$ durumda modeli oluşturmak için gözlem sayısının yeterli olduğu söylenebilir.

d. $F=87,81$ için $P$ değeri 0,1 'den çok küçük olduğu için model genel olarak yüksek derecede anlamlı çıkmıştır.

e. F ile $\mathrm{O}, \mathrm{M}, \mathrm{B}, \mathrm{K}$ ve $\mathrm{U}$ arasinda pozitif korelasyon vardır. Yani konut büyüdükçe, oda sayısı arttıkça ve bulunduğu kat ve apartman yükseldikçe konutun fiyat1 artmaktadır. Ayrıca model 1'den farklı olarak metroya olan uzaklık arttıkça konutun fiyatı artmaktadır çünkü konut metrodan uzaklaştıkça denize yaklaşmaktadır. $\mathrm{Bu}$ da evin fiyatını arttırır.

f. F ile Y arasında negatif korelasyon vardır. Yani konut yaşlandıkça fiyatı azalmaktadır.

\section{KONUT İSTATISTIKLERI}

$\mathrm{Bu}$ çalışmada 415 konut analiz edilmiş̧ir. Maltepe ilçesindeki konutların yaşı en az 1 en çok 41 'dir. İlçedeki konutların yaşının \%65 oranında 0-5 yaş arasında olduğu tespit edilmiştir. Tablo 12'de gösterilmiştir.

Tablo 12. Konutların yaş1

\begin{tabular}{|c|c|}
\hline Yaş aralığı (yıl) & Oran (\%) \\
\hline $0-5$ & 1 \\
\hline $5-15$ & 65 \\
\hline $15-25$ & 8 \\
\hline $25-35$ & 17 \\
\hline $35-45$ & 9 \\
\hline
\end{tabular}

Maltepe ilçesindeki konutların metrekaresi en az $30 \mathrm{~m}^{2}$ en çok $350 \mathrm{~m}^{2}$ 'dir. İlçedeki konutların metrekaresinin \%74 oranında $75-150 \mathrm{~m}^{2}$ arasında olduğu tespit edilmiştir. Tablo 13 'de gösterilmiştir.

Tablo 13. Konutların büyüklüğü

\begin{tabular}{|c|c|}
\hline Konut büyüklüğ̈̈ (m2) & Oran (\%) \\
\hline $0-75$ & 8 \\
\hline $75-150$ & 74 \\
\hline $150-225$ & 15 \\
\hline $225-350$ & 3 \\
\hline
\end{tabular}

Maltepe ilçesindeki konutların oda sayısı en az 1 en çok 8'dir. İlçedeki konutların oda sayısının \%41 oranında 3-4 arasında olduğu ve \%35 oranında 2-3 arasında olduğu tespit edilmiştir. Tablo 14'de gösterilmiştir.

Tablo 14. Konutların oda sayıs1

\begin{tabular}{|c|c|}
\hline Oda sayısı & Oran (\%) \\
\hline 1 & 8 \\
\hline 2 & 35 \\
\hline 3 & 41 \\
\hline 4 & 7 \\
\hline 5 & 7 \\
\hline 6 & 2 \\
\hline
\end{tabular}

Maltepe ilçesindeki konutların bulunduğu kat sayısı en az 1 en çok 23'dür. İlçedeki konutların bulunduğu kat sayısının \%81 oranında 5-10 arasında olduğu tespit edilmiş̧tir. Tablo 15 'de gösterilmiştir.

Tablo15. Konutların bulunduğu kat

\begin{tabular}{|c|c|}
\hline Konutun bulunduğu kat & Oran (\%) \\
\hline $0-5$ & 81 \\
\hline $5-10$ & 17 \\
\hline $10-15$ & 2 \\
\hline
\end{tabular}

Maltepe ilçesindeki binaların kat sayısı en az 2 en çok 30'dur. İlçedeki binaların kat sayısının \%71 oranında 5-10 arasında olduğu tespit edilmiştir. Tablo 16'da gösterilmiştir.

Tablo 16. Konutların kat sayıs1

\begin{tabular}{|c|c|}
\hline Kat sayısı & Oran \\
\hline $0-5$ & 71 \\
\hline $5-10$ & 21 \\
\hline $10-15$ & 3 \\
\hline $15-20$ & 2 \\
\hline $20-25$ & 2 \\
\hline $25-30$ & 1 \\
\hline
\end{tabular}


Maltepe ilçesindeki konutların metroya olan uzaklığı en az 9,08 m en çok 3143,31 m'dir. İlçedeki konutların metroya olan uzaklıklarının \%56 oranında 500-1500 m arasında olduğu tespit edilmiştir. Tablo 17'de gösterilmiştir.

Tablo 17. Konutların metroya uzaklığ

\begin{tabular}{|c|c|}
\hline Metroya uzaklık & Oran \\
\hline $0-500$ & 21 \\
\hline $500-1500$ & 56 \\
\hline $1500-2000$ & 15 \\
\hline $2000-2500$ & 5 \\
\hline $2500-3000$ & 2 \\
\hline $3000-3500$ & 1 \\
\hline
\end{tabular}

Maltepe ilçesi konut $\mathrm{m}^{2}$ birim fiyatları ile ilgili olarak, $\% 46$ oranında $1700 \mathrm{TL}$ ve $3750 \mathrm{TL}$ arasında fiyat aralığı gözlemlenirken aynı zamanda \%46 oranında $3750 \mathrm{TL}$ ve $5700 \mathrm{TL}$ arasında bir fiyat aralığının varlığından söz edilebilir. Tablo 18'de gösterilmiştir.

Tablo 18. Konutların birim fiyatları

\begin{tabular}{|c|c|}
\hline Birim Fiyat & Oran \\
\hline $0-3750$ & 46 \\
\hline $3750-5700$ & 46 \\
\hline $5700-7700$ & 7 \\
\hline $7700-9700$ & 1 \\
\hline
\end{tabular}

Maltepe ilçesi için mahalle bazında metrekare birim fiyatları aşağıdaki tabloda gösterildiği gibidir. İlçede ortalama $\mathrm{m}^{2}$ birim fiyat1 4158 TL'dir. Tablo 19'da gösterilmiş̧tir.

Tablo 19. Konutların $\mathrm{m}^{2}$ birim fiyatları

\begin{tabular}{|c|c|}
\hline İlçe & $\mathbf{m}^{\mathbf{2}}$ birim fiyatı (TL) \\
\hline Altayçeşme & 4444 \\
\hline Alııntepe & 4000 \\
\hline Aydınevler & 3500 \\
\hline Bağlarbaşı & 3909 \\
\hline Cevizli & 4222 \\
\hline Çınar & 3864 \\
\hline Feyzullah & 4574 \\
\hline Fındıklı & 2692 \\
\hline İdealtepe & 4389 \\
\hline Küçükyalı & 4200 \\
\hline Zümrütevler & 4300 \\
\hline
\end{tabular}

Maltepe ilçesindeki analiz yapılan 415 konutun fiyat dağılımı Tablo 20'de gösterilmiştir.
Tablo 20. Konutların fiyatları

\begin{tabular}{|c|c|}
\hline Fiyat aralı̆̆ & Oran \\
\hline $0-385000$ & 29 \\
\hline $385000-625000$ & 51 \\
\hline $625000-865000$ & 17 \\
\hline $865000-1000000$ & 2 \\
\hline 1000000 ve üzeri & 1 \\
\hline
\end{tabular}

\section{SONUÇ}

Maltepe ilçesinde Başıüyük ormanı, sahil yolu, E5 karayolu ve deniz bulunmaktadır. Ayrıca Maltepe sahil yolunda 1 milyon 200 bin metrekarelik dolgu alanına sahip bir sahil parkı yapılmıştır. Gülsuyu ve Gülensu mahallerinde ise İBB onaylı kentsel dönüşüm projeleri söz konusudur. Dolayısıyla Maltepe kendi içinde kompleks bir yapıya sahiptir. Analiz yapılırken bölgenin metro istasyonuna olan uzakl1ğıyla birlikte, çalışma alanını belirli kısımlara bölerek incelemek uygun görülmüştür. Bu nedenle Maltepe ilçesi iki bölgeye ayrılarak ilçedeki konut fiyatlarını belirleyen iki farklı regresyon modeli geliştirilmiştir.

Maltepe ilçesindeki konutların \%35'i 5 yaşından büyüktür. Konutun fiyatı ile yaşı arasında negatif bir ilişki olduğu görülmüş̧ür. Oluşturulan iki modelin sonucunda konut fiyatını etkileyen en önemli faktörün konutun metrekaresi olduğu bulunmuştur. Konutun metrekaresinin fiyatı üzerindeki etkisi 1. Bölge için \%49 iken 2. Bölge için \%60'dır. $\mathrm{Bu}$ oran metroya olan uzaklığın sahip olduğu etkinin yaklaşık 3 katıdır. Yani kişiler konut alırken yakın çevre değişkenlerinden çok konutun büyüklüğüne dikkate ederler. Konutlar zaten metrekare birim fiyatları üzerinden satılmaktadır. Maltepe ilçesi için genel olarak konut fiyatları, $400000 \mathrm{TL}$ ve $500000 \mathrm{TL}$ arasindadir. Konut ortalama $\mathrm{m}^{2}$ birim fiyat1 450000 TL civarındadır. Bununla birlikte, konutun bulunduğu kat ve oda sayısının fiyat üzerindeki etkisi istatistiksel olarak 1. Bölge için anlamlı çıkmamıştır. Dolayısıyla Model 1 için analiz yapılırken konutun oda sayısı ve kaçıncı katta olduğu dikkate alınmamıştır. Bu faktörlerin 1. Bölge için anlamsız çıkmasının nedeni, o bölgenin ticari faaliyet yerine daha çok konutlaşmaya yönelik olduğudur. 2. Bölge için ise oda sayısı ve konutun kaçıncı katta olduğu konut fiyatını sırası ile $\% 15$ ve $\% 13$ oranında etkilemektedir. Bunun nedeni daha pahalı ve değerli evlerin bulunduğu 2. Bölgede çok odalı ve yüksekte bulunan evlerin fiyatı daha da arttırmasıdır.

Her iki model için, metroya olan uzaklık istatistiksel olarak anlamlı çıkmıştır. 1. Bölge için metroya olan uzaklık konut fiyatını $\% 12$ oranında negatif yönde etkilemektedir. Konut fiyatı ile metroya olan uzaklık arasında negatif korelasyon vardır. Yani konutun metroya olan uzaklığı arttıkça 
fiyatı azalmaktadır. 2. Bölge için ise metroya olan uzaklık konut fiyatını \%19 oranında pozitif yönde etkilemektedir. Konut fiyatı ile metroya olan uzaklık arasında bu defa pozitif korelasyon vardır. Konutun metroya olan uzaklığı arttıkça fiyatı artmaktadır. Bunun nedeni 2. Bölgedeki mahallelerin konum olarak denize yakın olması ve bu bölgenin zaten oturmuş bir konut fiyat aralığına sahip olmasıdır. Metroya uzaklaştıkça denize yakınlaşıldığı için metroya yakınlık fiyatı bu defa olumsuz yönde etkilemiştir. 1. Bölge ve 2 . Bölge konum açısından kıyaslandığında 2. Bölge daha prestijlidir. Her iki bölge konutlaşma açısından kıyaslandığında ise 2. Bölgenin konutlaşma sürecinin büyük bir kısmını tamamladığ ve 1 . Bölgenin ise bu süreci devam ettirdiği tespit edilmiştir. Metrodan güneye doğru gidildikçe konutlar sahil kesimine doğru yaklaşmaktadır ve konutların fiyatları artmaktadır. Yani konutun metroya olan uzaklığından daha çok denize yakınlığı veya deniz manzarasına sahip olması konut fiyatını etkileyen konumsal bir faktördür. Altıntepe, Aydınevler, Girne, Zümrütevler, İdealtepe ve Küçükyalı mahalleleri metroya yürüme mesafesinde olmasına rağmen fiyatları Maltepe ilçesi için ortalama fiyat aralığındadır. Ancak Yalı, Feyzullah ve İdealtepe mahallesinin belirli bir bölümünde konut fiyatlarının ortalamanın üzerinde olduğu gözlemlenmektedir. Bunun nedeni konutların sahile yakın olmasıdır.

Metroya uzaklığın konutun metrekaresine göre daha az etkiye sahip olmasının nedeni diğer ulaşım alternatiflerinin de var olmasıdır. Maltepe ilçesinde ulaşım demiryolu ve karayolu ile yapılmaktadır. Demiryolu Maltepe'nin E-5 Karayolu altında kalan Eski Maltepe'nin kurulmuş olduğu güzergahtır. E5 karayolu ise Maltepe'yi üçe ayırmaktadır. Bu yol Maltepe'yi Anadolu'ya, yan yollar ise komşu ilçelere bağlar. İkinci önemli karayolu ise Bağdat Caddesi olup Bostancı ile Pendik arasındaki güzergahı oluşturmaktadır. Maltepe ilçesi ayrıca Kadıköy, Kartal, Sancaktepe ve Ataşehir ilçeleriyle komşudur. Ulaşım için birçok alternatif olduğu görülmektedir. Bu da Maltepe'de yaşayan kişilerin illa ki metro kullanmayı tercih etmek zorunda kalmayacaklarını gösterir.

Konutları etkileyen birçok fiziksel faktör olabilir. Bu bazı bölgelerde sahile yakınlık, bazı bölgeler için kent ormanına yakınlık, bazı bölgeler için ise konutun işlek bir cadde üzerinde olması olabilir. Yani konutların fiyatı aslında metroya olan uzaklı̆̆ından farklı olarak ilçenin semtlerine göre de değişmektedir. Bu sebepten sahile yakın olan Yalı Mahallesi aslında metroya en uzak mahallelerden biri olmasına karşın sahile yakın olması nedeniyle fiyatı yüksektir. Konut değerlemede etki yapan birçok faktör vardır. Modellemede daha fazla faktörün kullanılması, analiz sonucunda çıkan açıklanamayan nedenlerin belirlenmesini ve daha sağlıklı bir denklemin elde edilmesini sağlayacaktır.
Ulaşım yatırımlarının uzun vadedeki etkilerini tespit etmek ulaşım alt yapı yatırımından önce ve sonrasını değerlendirerek daha net bir sonuca götürebilir. Ancak ülkemizde bu konuda yapılan araştırma ve çalışmaların az olması, emlak sektöründe veri tabanının kısıtlı olması, uzun dönem için yapılacak olan çalışmalarda gerekli olan veriye ulaşmayı zorlaştırmaktadır. Bu durum bir yatırımın planlanması ve fizibilite çalışmalarında hata ya da yanılma oranını yükseltmektedir. Ayrıca bu çalışmadaki gibi matematiksel model kurularak emlak vergisi ve rayiç bedel değerleri konutun fiziksel ve konumsal nitelikleri ile belirlenebilir. Böylece değer belirlemedeki görecelik ortadan kalkarak daha doğru ve standart bir uygulamaya geçilmiş olur. Bu çalışmada regresyon modeli kullanılmıştır. Bunun yerine değişkenler arasında daha kapsamlı bir ilişki kurmak için farklı makine öğrenme yöntemleri kullanılabilir.

\section{KAYNAKLAR}

[1] GYODER, 2013 Gayrimenkul Sektörü ve İstanbul Konut Piyasası Saha Araştırma Raporu.

[2] Yalpır Ş., (2007). Bulanık Mantık Metodolojisi ile Taşınmaz Değerlenme Modelinin Geliştirilmesi ve Uygulaması: Konya Örneği. Doktora Tezi, Konya. Konya Selçuk Üniversitesi, Fen Bilimleri Enstitüsü.

[3] Damm, D., Lerman, S. R., Lerner-Lam, E., \& Young, J. (1980). Response of urban real estate values in anticipation of the Washington Metro. Journal of Transport Economics and Policy, 315-336.

[4] Forrest, D., Glen, J., \& Ward, R. (1996). The impact of a light rail system on the structure of house prices: a hedonic longitudinal study. Journal of Transport Economics and Policy, 15-29.

[5] Cervero, R. (2010, October). Effects of light and commuter rail transit on land prices: Experiences in San Diego County. In Journal of the Transportation Research Forum (Vol. 43, No. 1).

[6] Debrezion, G., Pels, E., \& Rietveld, P. (2004). The impact of railway stations on residential and commercial property value. Tinbergen Institute Discussion Paper

[7] Yankaya U. \& Çelik H. M., 2005. Kamu Ulaşım Yatırımlarının Gayrimenkul Değerleri Üzerine Etkisinin Modellenmesi: İzmir Metrosu Örneği. D.E.Ü. İ.İ.B.F. Dergisi Cilt: 20, Say1:2, Y11: 2005, ss:61-79

[8] Debrezion, G., Pels, E., \& Rietveld, P. (2011). The impact of rail transport on real estate prices: an empirical analysis of the Dutch housing market. Urban Studies, 48(5), 997-1015.

[9] Cerdà Troncoso, J. F., Pérez Prieto, C. B., \& Marmolejo Duarte, C. R. (2010). Impact real state value of urban and transportation projects, in the metropolitan area of Barcelona.

[10] Boucq, E. (2011). Estimating the impact on housing prices brought by a light rail infrastructure in France. 
[11] Hewitt, C. M., \& Hewitt, W. E. (2012). The effect of proximity to urban rail on housing prices in Ottawa. Journal of Public Transportation, 15(4), 3.

[12] Yan, B. (2012). Land Values Impacts of Subway Stations: A Case Study of Beijing City
[13] İnanoğlu, G. E., (2014). Kadıköy - Kartal raylı taşıma sistemi ve konut fiyatları değişiminin incelenmesi. Yüksek Lisans Tezi. İstanbul: Yıldız Teknik Üniversitesi FBE. 